\title{
The PABITRA Project: Island Landscapes under Global Change ${ }^{1}$
}

\author{
Dieter Mueller-Dombois ${ }^{2,3}$ and Curtis C. Daebler ${ }^{3}$
}

\begin{abstract}
The Pacific-Asia Biodiversity Transect (PABITRA) is a network of the Ecosystem Division in the Pacific Science Association's Task Force on Biodiversity. The PABITRA project seeks to develop a network of ocean-tomountain transects on islands across the Pacific to test hypotheses about biodiversity and promote sustainable use of island ecosystems under the influence of global change. A specific objective of PABITRA was to establish an oceanto-mountain transect in Fiji with major involvement of the resident islanders. Along this transect, a number of biodiversity study sites were to be selected for further research. The transect was established during two consecutive field workshops, from 18 November to 3 December 2002. Involved were 25 University of the South Pacific (USP) students, eight local faculty including Fiji Government and nongovernmental organization officials, and seven overseas collaborators. The outcome was documented in a 69-page illustrated report issued by the USP Institute of Applied Sciences as well as at a special symposium presented during the 20th Pacific Science Congress in Bangkok (17-21 March 2003) titled "Island Landscapes under Global Change: the PABITRA Project." Seven papers presented by members of the Fijian PABITRA group are published here, following this introductory paper. In addition, five papers introducing PABITRA activities outside Fiji are included in this special issue. The PABITRA project is ongoing and it is hoped that these papers will stimulate broad interest and participation in PABITRA's key objectives of promoting integrative resource management in Pacific Island environments.
\end{abstract}

A major objective of the Pacific-Asia Biodiversity Transect (PABITRA) is mutual capacity building through research and personal contacts for integrative resource management in insular environments. This is an urgent need for coping with the processes of global change. Global change is a broad concept. It involves complex changes in two major overlapping spheres, the environmental and socioeconomic spheres.

\footnotetext{
${ }^{1}$ Funding for this research as well as for travel of some participants to the 20th Pacific Science Congress in Bangkok was provided by Asia-Pacific Network for Global Change Research. Manuscript accepted 16 April 2004.

${ }^{2}$ Corresponding author (e-mail: AMDHawaii@aol .com).

${ }^{3}$ Department of Botany, University of Hawai $i$ at Mānoa, Honolulu, Hawai'i 96822.
}

Pacific Science (2005), vol. 59, no. 2:133-139

(C) 2005 by University of Hawaici Press

All rights reserved
Environmental changes are the documented rise in carbon dioxide and associated greenhouse gases. These gases produce chemical changes in the atmosphere, which are thought to increase global warming and to raise the frequency and intensity of climatic disturbances. The enhanced level of carbon dioxide also affects the world's vegetation by enhancing green-plant metabolism. Biological invasion of alien plants, animals, and disease organisms; increased fire frequency and intensity; loss of natural habitat; and habitat fragmentation are other global environmental changes of much concern. They cause ecosystem disturbance and landscape change on continents as well as islands (Mueller-Dombois 1992, 2001).

Socioeconomic changes are ongoing in part as a function of increasing human populations. These, in turn, affect rapidly changing market conditions, which are reflected in landscape and vegetation changes. Increased human mobility combined with the rapid transfer into the so-called "Information Age" 


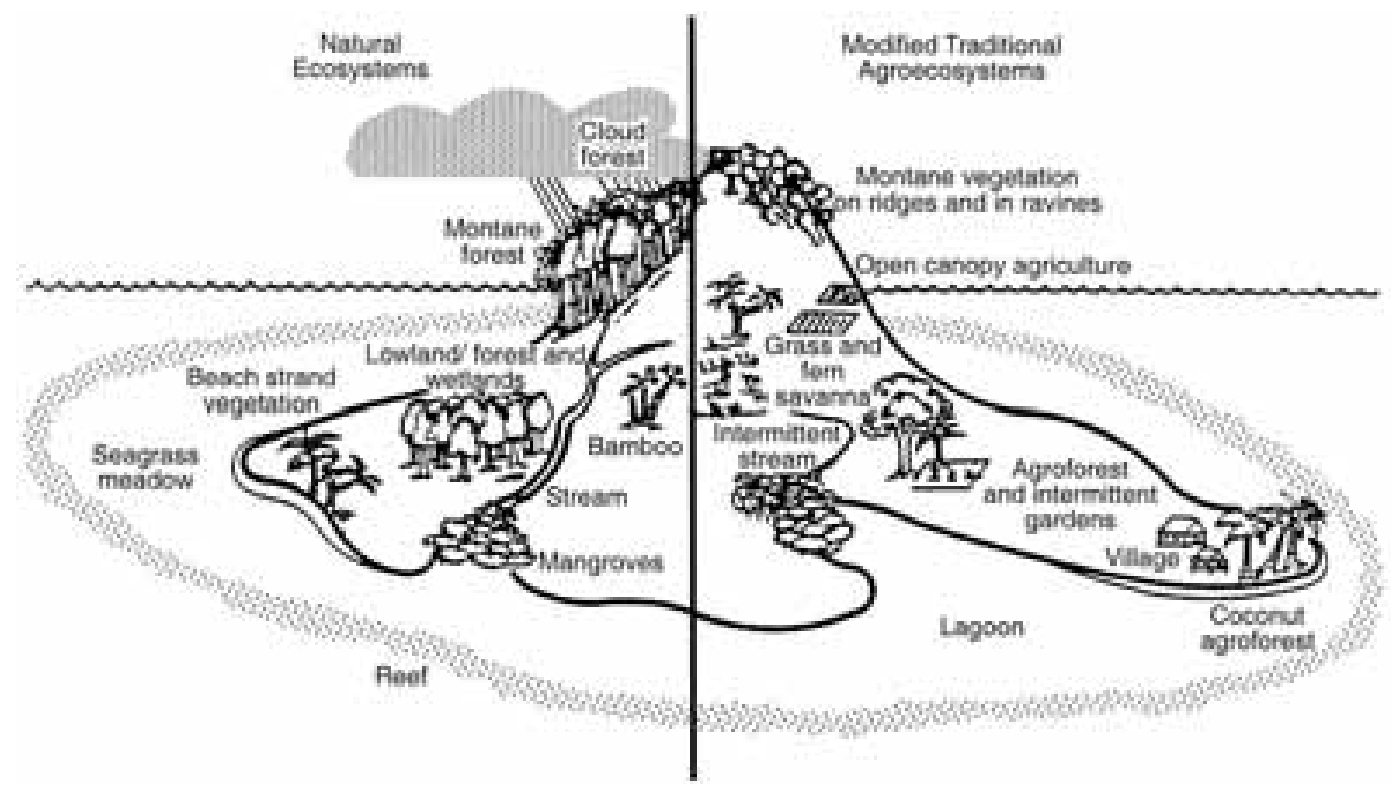

FIgURE 1. A high-island model. Reproduced with permission from Imamura and Towle (1987).

are the concomitant global change factors in the socioeconomic sphere. Moreover, the environmental and socioeconomic spheres are closely interwoven.

\section{INSULAR ENVIRONMENTS}

Insular environments by definition have narrowly limited biological resource zones. They include forest ecosystems, agroecosystems, freshwater ecosystems, and coastal saltwater ecosystems. These together form the traditional human support systems in islands. On high islands, these are found typically in a vertical topographic sequence as shown on the island model (Figure 1). Each of these larger ecosystems contains a variety of smaller ecosystems defined by their vegetation and habitat. For example, montane forests may include cloud forests and bogs; coastal ecosystems may include mangroves, estuaries, lagoons, and fringing reefs, to name a few.

An important aspect of the PABITRA methodology is to study the structure and function of ecosystems as individual units for their specific services but also to study their integration as interactive units in is- land landscapes. Disturbances impacting the upper-elevation ecosystems in a topographic sequence usually affect the lower lying ecosystems on that same landscape. Such related ecosystems should be studied cooperatively by multidisciplinary teams who consider the entire mountain-to-coast landscape a research unit. Consequently, island landscapes should be managed holistically so that human activities in one major ecosystem do not affect the other ecosystems negatively.

The PABITRA project aims (1) to acquire a basic knowledge of the evolution and history of island ecosystems; (2) to assess and monitor biodiversity and clarify its role in the functioning of ecosystems on a landscape basis; and (3) to adapt this knowledge to conservation management and policy.

\section{METHODOLOGY AND RESEARCH STRATEGY}

For accomplishing these aims of knowledge acquisition, PABITRA members work toward an easily understandable scientific methodology. For this, we are preparing a methods handbook with the title, "Biodiversity Assessment of Tropical Island Ecosystems," which 


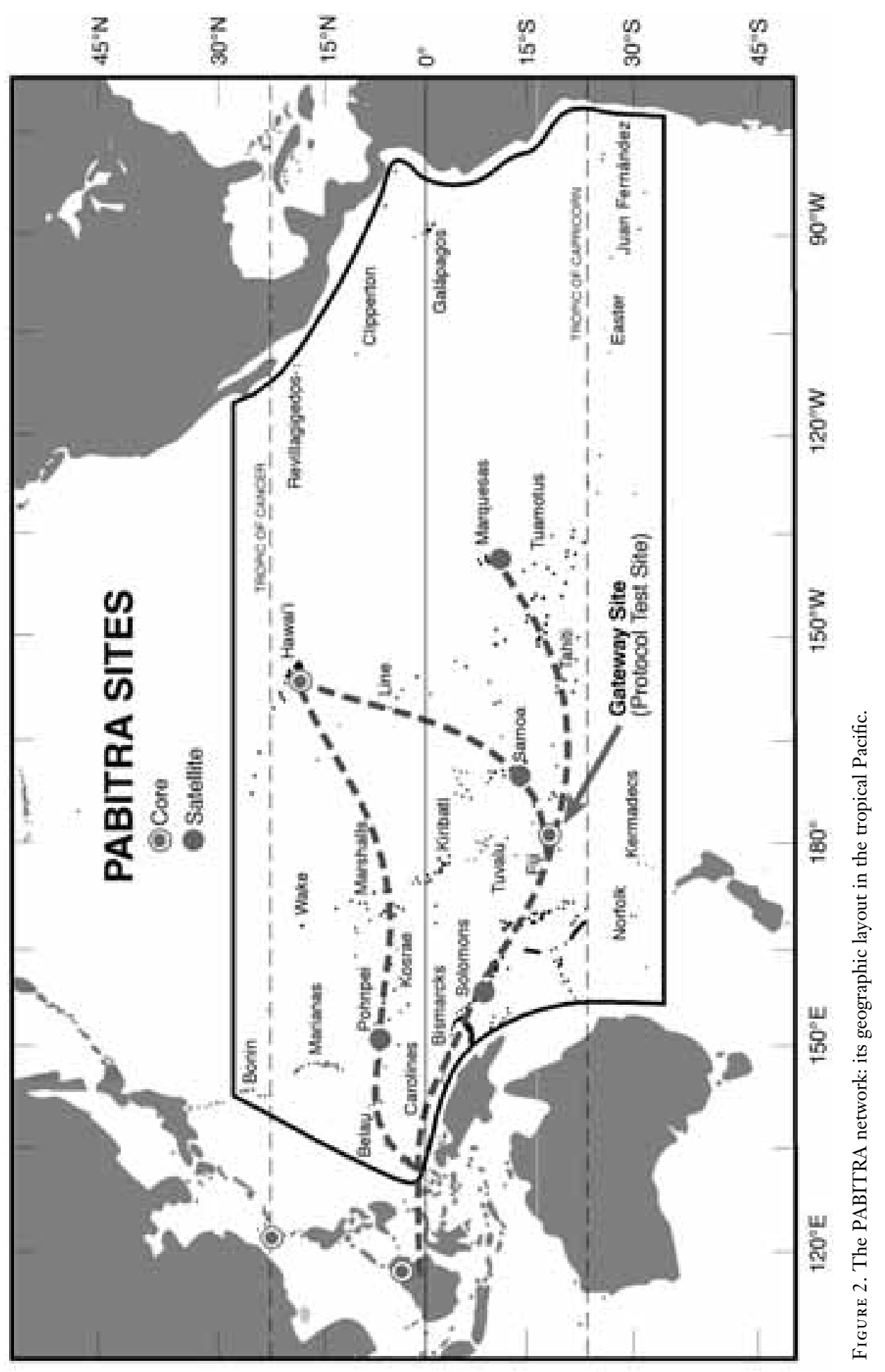




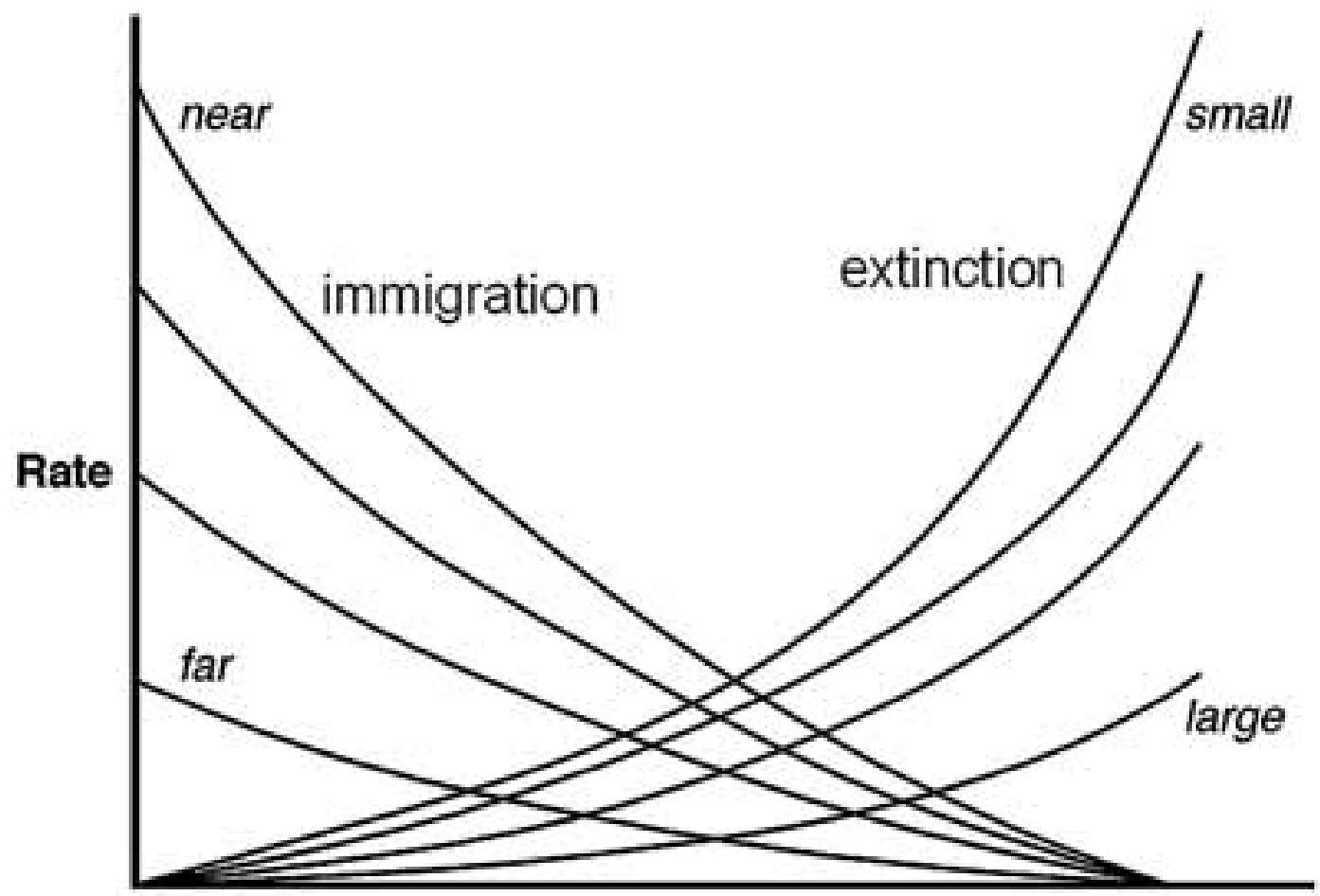

\section{Number of Species Present, N}

Figure 3. The island biogeography model of MacArthur and Wilson (1967).

is available on our Web site (www.botany .hawaii.edu/pabitra).

Some of the methodological aspects and problems are treated in the papers in this special PABITRA issue. The PABITRA network crosses the tropical Pacific Ocean from the outer islands of the paleotropics to the continental islands in the western Pacific (Figure 2). This geographic layout provides for an experimental approach of further testing and elaborating the inspirational theory of MacArthur and Wilson (1967) on island biogeography. The layout allows for a horizontal cross-island comparison of biodiversity structure and function of individual ecosystems that belong to the same Pacific-wide island biome. This is a departure from the original island biogeography theory, which considers only island size and distance as factors of biodiversity development in island ecosystems.
The Pacific offers many analogous environmental settings that are occupied with different sets of biodiversities, from far removed to near the source areas of the species-rich Asian Tropics (Mueller-Dombois 2002). In that geographic area, PABITRA is connected to DIWPA, the international network of DIVERSITAS in the Western Pacific and Asia. DIWPA has focused on a north-south biodiversity transect across Asia. The PABITRA and DIWPA networks interact frequently and have developed similar aims and methods (Yumoto 1999, Nakashizuka and Stork 2002).

The island biogeography model (Figure 3) of MacArthur and Wilson (1967) reminds us of the past, when islands, far removed from continental areas, received very slow rates of biological invasion. Today, even the faraway islands are impacted by formerly unexpected rates of biological invasion from continental 


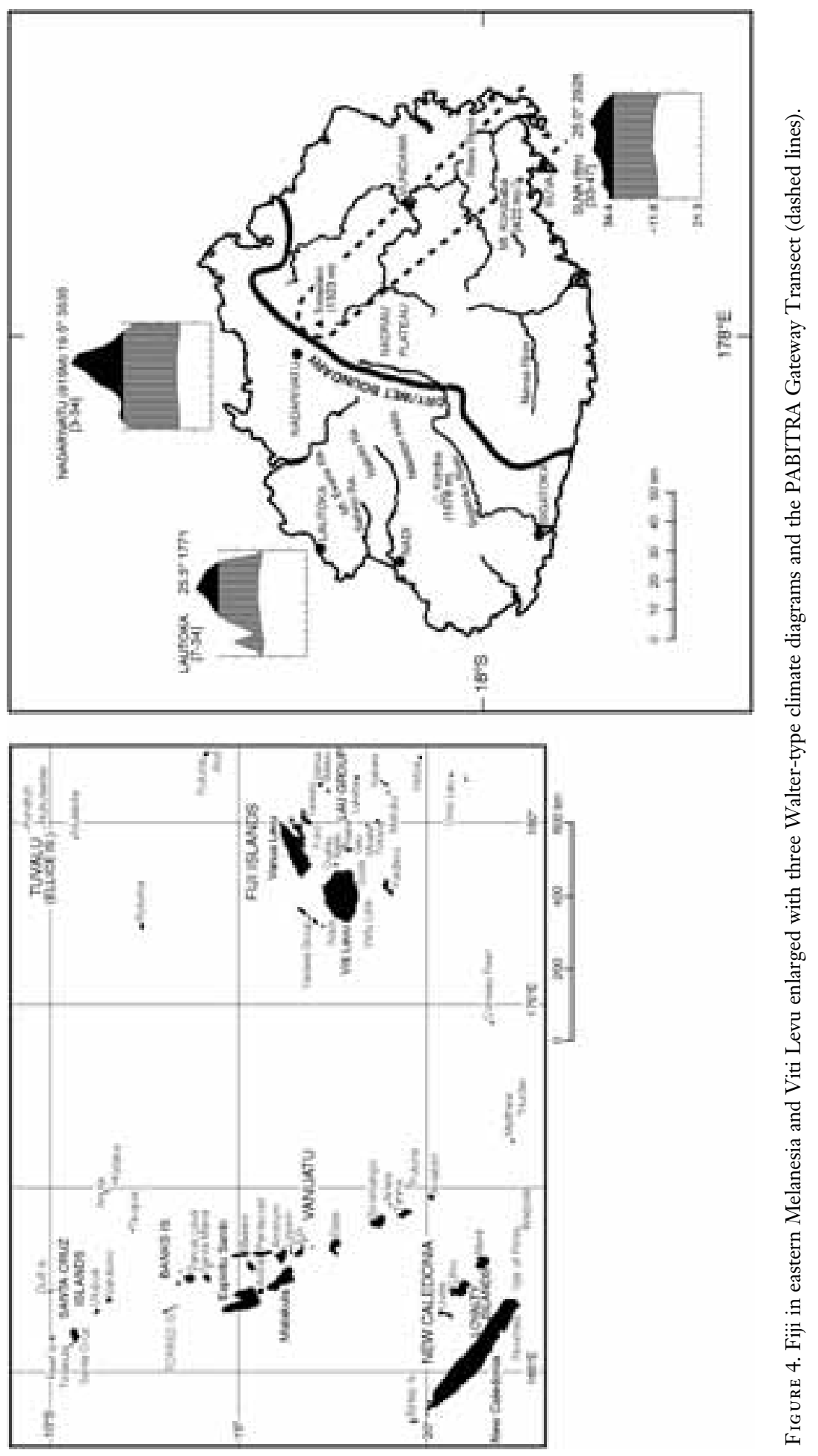


source areas. For example, Hawaiian landscapes in many areas are now changing into being dominated by fire-promoting African grasses (Daehler and Carino 1998). These are unwanted side effects of human activity.

On the positive side, small islands may not necessarily have a high rate of extinction of organisms as indicated in Figure 3. Protection from negative influences can achieve that. It is also possible to restore island ecosystems that have been exploited and to prevent negative trajectories that would lead to their destruction. An example is the eradication of rabbits on Philip Island, a small satellite island next to Norfolk Island (MuellerDombois and Fosberg 1998:192).

THE PABITRA GATEWAY TRANSECT IN FIJI

The Asia-Pacific Network for Global Change Research (APN)-sponsored PABITRA project in Fiji allowed for establishing a broad ocean-to-mountain landscape transect on Viti Levu's wet side. It extends from Nasoata Island in the ocean outflow area of the Rewa River into the upland rain forest near Mt. Tomaniivi $(1,323 \mathrm{~m})$. This more than 100km-long transect was considered the PABITRA Gateway and Protocol Test Site as designated on Figure 2.

Figure 4 displays a map of eastern Melanesia with the Fijian archipelago at its eastern side. An enlargement of Viti Levu with three representative Walter-type (1975) climate diagrams shows the approximate outline of the PABITRA Gateway Transect (dashed lines) in Viti Levu's wet zone. This is the focus of the papers following this introduction.

The papers following the Fijian contributions focus on Pohnpei and the Solomons, which are recognized as satellite PABITRA sites in Figure 2. In Micronesia, the PABITRA system passes through the Marshalls. Here, an atoll, recently proposed for World Heritage status, has received a rapid biodiversity assessment, and initial results are included in this special PABITRA issue. The final three papers relate to PABITRA research along an ocean-to-mountain transect on windward O'ahu (Hawaiian Islands). This O'ahu transect encompasses an ancient ahu- pua'a (traditional Hawaiian land-management unit) whose ecosystem services are in the process of being restored.

The type of research and integrative activities promoted by PABITRA can be challenging because success requires bringing together science, diverse cultural traditions, and policy to promote sustainable use and conservation of biodiversity and ecosystem services. But we have also found the PABITRA approach to be rewarding, because it has allowed us to build closer ties across the Pacific and gain a greater appreciation of human dimensions of biodiversity conservation. We hope that these papers will stimulate broad interest in the PABITRA approach and encourage future collaborations in biodiversity research on Pacific Islands.

\section{Literature Cited}

Daehler, C. C., and D. A. Carino. 1998. Recent replacement of native pili grass (Heteropogon contortus) by invasive African grasses in the Hawaiian Islands. Pac. Sci. 52:220-227.

Imamura, C. K., and E. Towle. 1987. Integrated renewable resource management for U.S. insular areas (Island study 1987). Paper Commissioned for the U.S. Office of Technology Assessment (OTA), Pacific Basin Development Council Research Institute, Honolulu.

MacArthur, R. H., and E. O. Wilson. 1967. The theory of island biogeography. Princeton University Press, Princeton, New Jersey.

Mueller-Dombois, D. 1992. Potential effects of the increase in carbon dioxide and climate change on the dynamics of vegetation. Water, Air, Soil Pollut. 64:6179.

. 2001. Biological invasion and fire in tropical biomes. Pages 112-121 in K. E. M. Galley and I. P. Wilson, eds. Proceedings, Invasive Species Workshop, Fire Conference 2000; the First International Congress on Fire Ecology, Prevention, and Management. Tall Timbers Res. Stn. Misc. Publ. 11. 2002. Forest vegetation across the 
tropical Pacific: A biogeographically complex region with many analogous environments. Plant Ecol. 163:155-176.

Mueller-Dombois, D., and F. R. Fosberg. 1998. Vegetation of the tropical Pacific Islands. Springer-Verlag, New York.

Nakashizuka, T., and N. Stork, eds. 2002. Biodiversity research methods: IBOY in western Pacific and Asia. Kyoto University Press, Kyoto.

Walter, H., E. Harnickel, and D. Mueller-
Dombois. 1975. Climate-diagram maps of individual continents and ecological climatic regions of the Earth. Springer Verlag, Berlin, Germany.

Yumoto, T. 1999. The objectives and protocols of IBOY 2001 (International Biodiversity Observation Year 2001). Pages 29-35 in C. H. Chou, G. R. Waller, and C. Reinhardt, eds. Biodiversity and allelopathy: From organisms to ecosystems in the Pacific. Academia Sinica, Taipei. 
